\title{
Analysis of the bacterial communities and endosymbionts of natural populations of Bemisia tabaci in several crop fields from Mexico semi-arid zone
}

\author{
Caamal-Chan María Goretty ${ }^{1}$ - Loera-Muro Abraham ${ }^{1} \cdot$ Castellanos Thelma $^{2} \cdot$ Aguilar-Martínez Carlos Julian $^{3}$. \\ Marfil-Santana Miguel David ${ }^{4}$ • Barraza Aarón ${ }^{1}$ (iD
}

Received: 15 February 2019 / Accepted: 14 May 2019 / Published online: 22 May 2019

(C) Università degli studi di Milano 2019

\begin{abstract}
Purpose Bemisia tabaci (Aleyrodidae family) is an insect vector of plant viruses that affects a wide variety of crops around the world. In the following study, we analyzed the variation in the bacterial communities associated with natural populations of B. tabaci (MEAM1) of four different crops from six regions from Mexico semi-arid zone (Baja California Sur).

Methods PCR was used to amplify the mitochondrial cytochrome oxidase I gene (mtCOI), and then to carry out the phylogenetic analysis for genetic identification of the isolated $B$. tabaci. Next generation sequencing coupled with $16 \mathrm{~S}$ metagenomic analysis was applied in order to characterize B. tabaci inner microbial community. Finally, bacterial obligate symbiont and facultative symbiont were confirmed by PCR amplification and by phylogenetic analysis.

Results Ours results pointed toward that $B$. tabaci MEAM1 inner bacterial communities were predominantly structured by Proteobacteria phylum. Moreover, the most represented endosymbionts were the obligate endosymbiont from the genus "Candidatus Portiera", as well as two facultative symbionts belonging to genera Rickettsia and Hamiltonella; both obligate and facultative endosymbionts were present for all samples, and their relative abundance varied was crop-independent.

Conclusions Geographic localization and insect diet play a central role to maintain bacterial community structure of the $B$. tabaci MEAM1 whitefly at phylum taxonomic level. Agricultural practices were a factor that affected samples of bacterial community structure similarities, reflected in samples clustering. Host plants that are part of B. tabaci diet did not influence directly, in spite of sap nutrient differences, into obligate and facultative endosymbionts relative abundance.
\end{abstract}

Keywords Bemisia tabaci $\cdot$ Bacterial communities $\cdot$ Endosymbiont $\cdot$ Environmental factors

The sequence in this paper has been deposited in the National Center for Biotechnology information under the BioProject accession no.

PRJNA521383. The GenBank/EMBL/DDBJ accession numbers for 16S rRNA sequence of the assessed samples are: Rickettsia (MK159392),

Portiera (MK208462), "Candidatus Hamiltonella defensa"

(MK280777). The GenBanK accession number for Bemisia tabaci mtCOI gene is (MK169413).

Electronic supplementary material The online version of this article (https://doi.org/10.1007/s13213-019-01483-6) contains supplementary material, which is available to authorized users.

Barraza Aarón

abarraza@cibnor.mx

1 CONACYT-Centro de Investigaciones Biológicas del Noroeste SC, Instituto Politécnico Nacional 195, Playa Palo de Santa Rita Sur, C.P.23096 La Paz, BCS, Mexico

2 Centro de Investigaciones Biológicas del Noroeste, SC, Instituto Politécnico Nacional 195, Playa Palo de Santa Rita Sur, C.P. 23096 La Paz, BCS, Mexico
3 Instituto Tecnológico de La Paz, Boulevard Forjadores de Baja California Sur 4720, 8 de Octubre 2da Secc, C.P. 23080 La Paz, BCS, Mexico

4 Facultad de Química, Unidad Sisal, Universidad Nacional Autónoma de México, Puerto de Abrigo, C.P. 97356 Sisal, Yucatán, Mexico 


\section{Introduction}

Animals are a nutrient-rich habitat for microorganisms with the ability to modulate animal immune system and metabolic adaptations to colonize and utilize host resources (Kostic et al. 2013; Chung et al. 2017). The association between insects and microbial organisms is quite important for ecological diversification and evolution of insects' feeding habits. The next generation sequencing (NGS) has emerged as an important tool to describe the microbiota structure from environmental and biological samples such as insect pest, suggesting that associated microbiota plays an important role in protection against plants defenses, resistance to insecticides, temperature, reproduction, and even contributing in host nutrition (Weiss and Aksoy 2011; Su et al. 2016; Mereghetti et al. 2017; Chung et al. 2017).

The ability of insects to adapt into certain nutritional lifestyles can be attributed to survival strategies that also include associations with obligate symbionts or "primary bacterial symbionts" which have been characterized in several insect groups, such as Buchnera in aphids, "Candidatus Portiera" in whiteflies and Carsonella in psyllids. The associations of insects with facultative endosymbionts or "secondary endosymbionts" are not essential for host survival, such as Rickettsia, Hamiltonella, and Cardinium in whiteflies and Arsenophonus in psyllids and aphids, but these endosymbionts can manipulate hosts in many other ways, such as genetic differentiation, adaptation to a wide range of food plants, defense against natural enemies, reproduction, insecticide resistance, and pathogen transmission (Chuche et al. 2017).

Bemisia tabaci is recognized as a cryptic species complex, a small sap-sucking insect known as whitefly that is capable of damaging a wide range of agricultural products through its feeding activity and its active role in plant viruses transmission (De Barro et al. 2011). Phylogenetic analyses applied for $B$. tabaci were based on the mitochondrial cytochrome oxidase I gene marker (mtCOI) and have been shown that there are four major geographically defined clades: (i) sub-Saharan African, (ii) New World, (iii) Asia, and (iv) Africa/Middle East/Asia Minor/Central Asia/Mediterranean. From those regions, the B. tabaci varieties that belong to clade IV, Mediterranean (MED), and Middle East-Asia Minor 1 (MEAM1) have become into some of the most damaging agricultural pests, which are biologically differentiated and reproductively isolated from each other (Boykin et al. 2007, 2013). Both B. tabaci biotype species (MED and MEAM1) have also been reported in the American continent, with frequent invasion into several crop fields giving rise to genetic material exchange process and increasing pest traits (Elfekih et al. 2018). B. tabaci is an insect that its mouthparts were developed for piercing and sucking, and derived by its feeding habits has established a symbiotic relationship with bacteria of genus "Candidatus Portiera", that is an obligate symbiont, but also with facultative symbionts of several genera including Rickettsia, Hamiltonella, Wolbachia, Arsenophonus, Cardinium, and Fritschea (Gnankiné et al. 2013). Recent progress has been made in whitefly-plants interactions to determine the role of facultative symbionts, such as Hamiltonella that plays a central role abolishing tomato plant defense, and also has been related in Tomato yellow leaf curl virus (TYLCV) transmission (Su et al. 2013, 2015). In addition, it has been determined that Rickettsia presence is directly related to heat tolerance and protection against the entomopathogenic Pseudomonas syringae in B. tabaci (Brumin et al. 2011; Hendry et al. 2014).

Most of insect symbionts are vertically transmitted although recent works have provided evidence of horizontal transmission by experiments with axenic larvae that were fed with plants possessing Rickettsia, and then those insects in adult stages were analyzed by PCR to detect Rickettsia $16 \mathrm{~S}$ rDNA gene sequence (Chrostek et al. 2017; Li et al. 2017a; Li et al. 2017b). The prevalence of facultative symbionts is often attributed to multiple factors, including climate, geographical localization, geographical isolation (surrounded by deserts, mountains, rivers, sea, absence of appropriate host plants), horizontal transmission, and insect host plant, in natural populations of B. tabaci, and other insects (Pan et al. 2012; Jing et al. 2014; Zhu et al. 2018). The insect microbial communities have been characterized mainly by PCR-based detection techniques focused on 16S rDNA or 23S rDNA gene amplification. Nowadays, the 16S rDNA metagenomic analysis of phloem sap from which insects were fed has opened the landscape about exploring ecological questions. Specifically, in B. tabaci, it has been determined that the associated bacterial community structure does not differ significantly between insects bred in laboratory and collected from crop fields, and, in both insect populations, obligate symbionts and facultative symbionts were the most abundant (Jing et al. 2014). Furthermore, the work with $B$. tabaci fed in laboratory with several plant species shed light into the essential role of host plant for shaping the whitefly-associated bacterial community structure (Su et al. 2016).

Baja California peninsula in Mexico offers climatological, geographical, and agricultural features that favor high populations of whitefly, such as relative geographical isolation and intensive agriculture in well-defined and isolated areas with a low diversity of plant species that favor the bacteria able to colonize the whitefly gut, and a semi-arid weather to study whiteflies' natural populations and their associated bacterial communities. We analyzed the variation in the bacterial communities and endosymbionts associated with natural populations of B. tabaci of four different crops, from six regions, from this semi-arid zone (Baja California Sur) of Mexico to assess the impact of host plants, geographical localization, and agricultural practices (Fig. S1). 


\section{Materials and methods}

\section{Whitefly population collection}

The whiteflies used in this study were natural populations of B. tabaci collected in six sites from the Baja California peninsula (south region), Mexico, during the time period of 20162017. The crop plant species (host-plant) localization were (i) La Matanza (23 $\left.39^{\prime} 26.2^{\prime \prime} \mathrm{N}, 110^{\circ} 16^{\prime} 00.3^{\prime \prime} \mathrm{W}\right)$ with Solanum lycopersicum (1T) and Capsicum annuum var. serrano $(2 \mathrm{CH})$ (two samples); (ii) El Comitán (24 08' 06.6" $\left.\mathrm{N}, 110^{\circ} 25^{\prime} 40.3^{\prime \prime} \mathrm{W}\right)$ with $C$. chinense $(4 \mathrm{H})$ and $C$. annuum var. poblano (5P) (two samples); (iii) Los Planes (23 $55^{\prime}$ $58.1^{\prime \prime} \mathrm{N}, 109^{\circ} 54^{\prime} 33.1^{\prime \prime} \mathrm{W}$ ) with Cucurbita pepo (3CO) and Brassica oleracea var. gemmifera (8CA) (two samples); (iv) El Valle (250 $\left.04^{\prime} 04.7^{\prime \prime} \mathrm{N}, 111^{\circ} 36^{\prime} 17.4^{\prime \prime} \mathrm{W}\right)$ with $C$. pepo (two samples: 6CA and 7CA); (v) El Carrizal (23 48' 01.1" $\mathrm{N}, 110^{\circ} 17^{\prime} 39.1^{\prime \prime} \mathrm{W}$ ) with C. pepo (one sample: 10CA); and (vi) El Pescadero (23 $\left.23^{\prime} 39.8^{\prime \prime} \mathrm{N}, 110^{\circ} 10^{\prime} 28.9^{\prime \prime} \mathrm{W}\right)$ with C. pepo (one sample: 9CA); totaling ten samples (Table 1). The whiteflies (in adult stage) collected were carried out during their feeding periods and placed in 95\% $(v / v)$ ethanol until total DNA extraction.

\section{DNA extraction}

Whiteflies in adult stage (white color insect body, red eyes) were previously identified with the aid of a stereoscope, for every localization and crop (Azab et al. 1969; Rosell et al. 1995). Twenty-one whiteflies were pooled per localization and host-plant (sample) $(21$ insects $\times 10$ pool samples $=21$ insects/pool sample $=210$ insects). Those insects positively identified were processed and described as follows: each insect pooled sample was washed three times with $70 \%(v / v)$ ethanol and the supernatant was removed; each pooled sample was processed with plastic micropestle and $800 \mu \mathrm{L}$ of DNA extraction buffer ( $2 \%$ CTAB, $1.4 \mathrm{M} \mathrm{NaCl}, 20 \mathrm{mM}$ EDTA, $100 \mathrm{mM}$ Tris-HCl pH 8.0, 0.2\% $\beta$-mercaptoethanol, $1 \mathrm{mg} /$ $\mathrm{mL}$ Proteinase K) (Chen et al. 2015), incubated at $55^{\circ} \mathrm{C}$ for 60 min with occasional stirring, followed by the addition of one volume of chloroform:isoamyl alcohol (24:1), and centrifuged for $15 \mathrm{~min}$ at $12,000 \times \mathrm{g}$. After that, one volume of isopropyl alcohol (Sigma-Aldrich, USA) was added and incubated overnight at $-20^{\circ} \mathrm{C}$. DNA was precipitated by centrifugation at $12,000 \times \mathrm{g}$ for $10 \mathrm{~min}$, and then washed with $70 \%(\mathrm{v} / \mathrm{v})$ ethanol followed by centrifugation at $12,000 \times g$. The DNA pellet was resuspended in $40 \mu \mathrm{L}$ of ultra-pure distilled water. Total DNA samples were treated with RNase A $(10 \mathrm{mg} / \mathrm{mL})$ (Promega, Madison, WI, USA) and incubated at $37^{\circ} \mathrm{C}$ for $30 \mathrm{~min}$. Total DNA (100-200 ng) integrity for each sample was verified by agarose $0.9 \%(w / v)$ gel electrophoresis, and its quality was assessed with the ratio of $\lambda 260 \mathrm{~nm} / 280 \mathrm{~nm}$ (from 1.79 to 2.00) with a spectrophotometer NanoDrop 2000 (Thermo Fisher Scientific, Waltham, MA, USA). Finally, the samples were stored at $-20^{\circ} \mathrm{C}$ for its preservation.

\section{Detection of B. tabaci species (mtCOI gene)}

The mitochondrial cytochrome oxidase I (mtCOI) gene from whitefly samples was amplified using biotype-specific primers reported for Shatters et al. (2009). PCR reactions were performed using $0.25 \mathrm{mM}$ of each primer, $0.5-\mathrm{mM}$ deoxynucleotide triphosphates (dNTPs), $1.5-\mathrm{mM} \mathrm{MgCl}_{2}$, $0.5 \mu \mathrm{L}$ of Taq DNA polymerase buffer, $1 \mathrm{u}$ of GoTaq (Promega, Madison, WI, USA), and 100 ng of DNA. PCR reaction was carried out as follows: initial denaturation step ( $95{ }^{\circ} \mathrm{C}, 5 \mathrm{~min}, 1$ cycle), amplification step for 35 cycles $\left(95{ }^{\circ} \mathrm{C}, 30 \mathrm{~s} ; 64{ }^{\circ} \mathrm{C}, 1 \mathrm{~min}\right.$ and $72{ }^{\circ} \mathrm{C}, 1 \mathrm{~min}$ ), and a final extension at $72{ }^{\circ} \mathrm{C}$ for $5 \mathrm{~min}$. PCR amplification was purified using the Zymoclean ${ }^{\mathrm{TM}}$ Gel DNA Recovery Kit (Zymo Research, Irvine, California, USA) and Sanger sequenced. The accession number for the B. tabaci identified is MK169413.
Table 1 Descriptive information of each sample collected in Baja California peninsula in Mexico used in this study

\begin{tabular}{llllll}
\hline $\begin{array}{l}\text { Sample } \\
\text { ID }\end{array}$ & Localization & Host plant & $\begin{array}{l}\text { Family of } \\
\text { plants }\end{array}$ & $\begin{array}{l}\text { Agriculture } \\
\text { practice* }\end{array}$ & $\begin{array}{l}\text { Collection date } \\
\text { day-month-year }\end{array}$ \\
\hline 1TO & La Matanza & S. lycopersicum & Solanaceae & Treated & $14-06-2017$ \\
$2 \mathrm{CH}$ & La Matanza & C. annuum & Solanaceae & Treated & $14-06-2017$ \\
3CO & Los Planes & B. oleracea & Brassicaceae & Treated & $31-03-2017$ \\
4H & Comitán & C. chinense & Solanaceae & Untreated & $09-05-2017$ \\
$5 \mathrm{P}$ & Comitán & C. annuum & Solanaceae & Untreated & $02-06-2017$ \\
$6 \mathrm{CA}$ & El Valle & C. pepo & Cucurbitaceae & Untreated & $20-02-2017$ \\
$7 \mathrm{CA}$ & El Valle & C. pepo & Cucurbitaceae & Untreated & $20-02-2017$ \\
$8 \mathrm{CA}$ & Los Planes & C. pepo & Cucurbitaceae & Treated & $24-11-2017$ \\
$9 \mathrm{CA}$ & Pescadero & C. pepo & Cucurbitaceae & Treated & $03-12-2016$ \\
$10 \mathrm{CA}$ & Carrizal & C. pepo & Cucurbitaceae & Treated & $30-03-2017$ \\
\hline
\end{tabular}

*This column indicates whether pesticides or agrochemicals (La Matanza, Los Planes, Pescadero, and Carrizal) were used regularly or not (Comitán, El Valle) 


\section{$16 S$ V3 rDNA sequencing}

DNA of 21 whiteflies were pooled and processed as one sample that represents a localization and host-plant. A total of ten DNA pools were used to amplify the V3-V4 region of the $16 \mathrm{~S}$ rDNA gene using the primers V3$338 \mathrm{~F}$ and V4-806R. The product was used as template for the second round of amplification using the primers V3-338F and V3-533r containing Illumina adapters. Samples were sequenced on the Illumina MiniSeq platform $2 \times 150$ (300 cycles). The resulting sequences were deposited in the GenBank under the BioProject accession number PRJNA521383.

\section{Metagenomic analysis}

For relative abundance analysis of endosymbionts, unassembled DNA sequences were annotated with Metagenomics Rapid Annotation using Subsystems Technology (MGRAST) pipeline version 3.5 for downstream analyses (htt:// metagenomic.anl.gov; Meyer et al. 2008). Taxonomic assignments were performed using the normalized abundance of sequence matches to M5nr and SILVA SSU database. For data normalization, the frequency of representative hits to each individual taxon for each metagenome was divided by the total number of hits. To identify hits, Blastn was employed with a maximum $E$-value of $1 \mathrm{e}-05$, a minimum identity of $97 \%$, and maximum alignment of $15 \mathrm{bp}$ obtained from MG-RAST server was downloaded and analyzed. The sequences were deposited in MG-RAST under the project "whitefly Baja California" (ID 82439).

In addition, Illumina MiniSeq sequencing reads were subjected to quality filtering $(Q \geq 33)$ using the modified Mott algorithm; sequences were paired-end, and then merged with BBmerge (Ewing et al. 1998; Ewing and Green 1998; Kearse et al. 2012; Bushnell et al. 2017). Those sequence reads were then de novo assembled with Geneious Assembler algorithm of Geneious R10.2 (www.geneious.com), with a minimum identity of $98 \%$, and both contigs and unassembled reads were compared against the GenBank non-redundant ("nt-nr") database using Megablast (Randle-Boggis et al. 2016). Megablast results were used to create a curated database specific for each pool sample. Sequence reads per pool sample were clustered against its corresponding created database using Sequence Classifier plugin, with a minimum of $99 \%$ identity for species taxonomic assignation, to finally obtain the table of operational taxonomic units (OTUs) frequencies using Geneious R10.2, (www.geneious.com). The resulting OTUs tables were then processed to be analyzed with $\mathrm{R}$ programming language using a variety of packages and custom scripts (www.r-project.org). We estimated Chao1, Shannon, and Simpson (alpha) biodiversity indices with the package "vegan". PERMANOVA statistical analysis was performed with "adonis" function with the package "vegan", and ANOVA analysis followed with Tukey post hoc test with "HSD.test" function with the package "agricolae". Bray-Curtis distance estimations were calculated using the "vegdist" function, as well as principal component analysis using "prcomp" function with the package "ggfortify" (Oksanen et al. 2014; Coleman-Derr et al. 2016; Castañeda and Barbosa 2017).

\section{Detection of whitefly symbionts}

The obligate symbiont (bacteria from genus "Candidatus Portiera") and facultative symbionts (bacteria from genera Rickettsia, Hamiltonella, Cardinium, Wolbachia, Fritschea, Arsenophonus) PCR-based detections were performed using specific primer sequences (Portiera: 28F and 1098R, Rickettsia: Rb-F and Rb-R, Hamiltonella: Ham-F and Ham-R, Cardinium: CFB-F and CFB-R, Wolbachia: wsp81-F and wsp691-R, Fritschea: U23F and 23SIGR, Arsenophonus: Ars23S-1 and Ars23S-2) reported in Pan et al. (2012). PCR reactions were performed with $100 \mathrm{ng}$ of DNA as follows: initial denaturation step (95 ${ }^{\circ} \mathrm{C}, 5 \mathrm{~min}, 1$ cycle), amplification step for 35 cycles $\left(95{ }^{\circ} \mathrm{C}, 30 \mathrm{~s}\right.$ denaturation; annealing $55^{\circ} \mathrm{C}$ (Wolbachia)), $58{ }^{\circ} \mathrm{C}$ ("Candidatus Portiera", Cardinium, Arsenophonus, and Hamiltonella), $60{ }^{\circ} \mathrm{C}$ (Rickettsia and Fritschea for $1 \mathrm{~min}$; and extension $72^{\circ} \mathrm{C}, 1 \mathrm{~min}$ ), and a final extension at $72{ }^{\circ} \mathrm{C}$ for $5 \mathrm{~min}$. The PCR amplification products were purified using the Zymoclean ${ }^{\mathrm{TM}}$ Gel DNA Recovery Kit (Irvine, California, USA) and Sanger sequenced. The accession numbers for 16S rDNA sequences of the assessed samples are Rickettsia (MK159392), Portiera (MK208462), "Candidatus Hamiltonella defensa" (MK280777).

\section{Phylogenetic analysis of species of $B$. tabaci and bacterial endosymbionts}

The mtCOI gene for B. tabaci, and 16S rDNA and 23S rDNA for bacterial endosymbionts sequences were obtained from GenBank and with the consensus sequence from each sample (three obtained sequences per sample were aligned and assembled to yield a consensus sequence) obtained in this work to be phylogenetically analyzed. The sequences alignment was carried out with MUSCLE with default parameters, and phylogenetic analysis was performed with maximum likelihood (ML) methodology coupled with Kimura-2 parameter model, and 1500 replicates of bootstrap for statistical support of evolutionary branch lengths, with Molecular Evolutionary Genetic Analysis software package version 7 (MEGA7) (Kumar et al. 2016). 


\section{Results}

\section{Genetic identification of $B$. tabaci based on $\mathrm{mtCO}$}

All B. tabaci collected samples were addressed through PCRbased biotype species identification using the mtCOI gene marker, as well as their corresponding phylogenetic analysis to support the identification. The resulting PCR-based species identification for all B. tabaci samples were positive for biotype MEAM1 (Fig. S2). $B$. tabaci mtCOI marker gene phylogenetic analysis confirmed that whiteflies' natural populations of the Baja California peninsula south region belong to biotype MEAM1 (MEAM1_MEX_BCS) by the monophyletic grouping with other biotype MEAM1, and also had an evolutionary close relationship with the $B$. tabaci MEAM1 isolate from Brazil (Fig. 1).

\section{Microbial community diversity and composition of B. tabaci MEAM1}

To characterize the bacterial community structures in $\mathrm{B}$. tabaci biotype MEAM1_MEX_BCS natural populations from Baja California peninsula south region (Table 1), we proceed with 16S rDNA metagenomic analysis. The analysis was conducted for ten samples which represent four different crops from six regions. The number of yielded raw reads per pool sample was as follows: $1 \mathrm{~T}, 160686$ reads; $2 \mathrm{CH}, 162,672$ reads; $3 \mathrm{CO}$, 179,140 reads; $4 \mathrm{H}, 165,424$ reads; $5 \mathrm{P}, 180,306$ reads; $6 \mathrm{CA}$, 170,192 reads; 7CA, 147,540 reads; $8 \mathrm{CA}, 200,446$ reads; 9CA, 194,206 reads; and 10CA, 119,364 reads. We obtained 755,360 paired-end sequence reads after quality filtering (from 1,679,976 total reads, 1,510,720 reads were above a phred of 33, and then paired-end merged), for all (ten) collected samples. The percentage of reads did not match to any known operational taxonomic unit (OTU) in the GenBank nucleotide non-redundant (" $n t-n r$ ") database was of $2.602 \%$. We were able to obtain 2093 OTUs, and after singleton removal, we obtained 1209 OTUs.

The alpha diversity indices were estimated to determine bacterial community abundance (observed OTUs, Chao1 index), richness (Shannon), and homogeneity (Simpson) for B. tabaci MEAM1 collected samples. Bacterial community abundance indicated by observed OTUs and Chaol index estimation was relatively low, as expected, by the low OTUs abundance that were represented by a single read, for all B. tabaci MEAM1 collected samples, and supported by the Shannon index $(2.533 \pm 0.207)$. Interestingly, the Simpson index $(0.94 \pm 0.02)$ showed a homogenous bacterial composition for all B. tabaci MEAM1 collected samples (Table 2). It is worth noting that both, Chao1 index and Simpson index, reflect the stability of gut microbiota as a discrete and well- defined ecosystem to promote the proliferation of certain and specific bacterial groups, and only influenced by the insects' feeding habits.

Furthermore, we found for all collected samples ten phyla such as including Proteobacteria, Acidobacteria, Actinobacteria, Firmicutes, Bacteroidetes, Chloroflexi, Cyanobacteria, Planctomycetes, Tenericutes, and Verrucomicrobia. The dominant phylum in $B$. tabaci MEAM1 MEX BCS was Proteobacteria (the relative abundances of 96-99\%). Two classes of Proteobacteria phylum were the most abundant: Gammaproteobacteria (58-75\%) and Alphaproteobacteria (0.060-40\%). The Gammaproteobacteria class was mainly conformed by two of genera "Candidatus Portiera" (24-54\%) and Hamiltonella (17.93-44\%). The Alphaproteobacteria class was mainly conformed by the genus Rickettsia $(0.011-39.34 \%$,$) . The remaining phyla$ also exhibited low abundance frequencies $(\sim 3-<0.6 \%)$ (Fig. 2). The endosymbionts (obligate and facultative) of B. tabaci MEAM1_MEX_BCS belong to Proteobacteria phylum, and this fact could represent a major contribution into crop production, since it is possible to develop strategies focused against those (endosymbionts) bacteria to decrease or eliminate their abundance in crop fields.

We procced with $\beta$-diversity analysis based in Bray-Curtis distances estimation to determine sample hierarchical clustering, and a principal component analysis (PCA) to address the impact of host plant species, localizations, and agrochemicals application (agricultural practices) on bacterial community structure of $B$. tabaci MEAM1. PCA analysis showed three discrete and well-defined groups or samples clustering: (i) 10CA, 1T, 9CA, and 8CA; (ii) 7CA, 3CO, 4H, 6CA, and 5P; and (iii) $2 \mathrm{CH}$ (Fig. 3). To test the effect of host plant species, localization of crop fields, and agricultural practices on the observed variations on bacterial community structure of B. tabaci MEAM1, permutational multivariate analysis of variance (PERMANOVA) was performed. PERMANOVA confirmed that agrochemicals application was the main factor (host plant species and localization were not statistically significant) that exerted the effect on the bacterial community structure clustering $\left(R^{2}=0.2971, P=0.007\right)$, determined in PCA analysis (Fig. 3). These sample grouping was also supported by the hierarchical clustering analysis derived from the Bray-Curtis distances estimation (Fig. S3), and also by an analysis of correlation among samples and heatmap analysis (Fig. S4 and Fig. S5, respectively).

\section{Host plant effect on whitefly symbiont abundances}

The whitefly symbionts relative abundance was assessed from eight samples collected, excepting both $3 \mathrm{CO}$ (family Brassicaceae) and 7CA ("El Valle" repeated sample) samples, and divided into two groups based on the plant host family: Solanaceae (1T, 2CH, 4H, 5P) and Cucurbitaceae (6CA, 


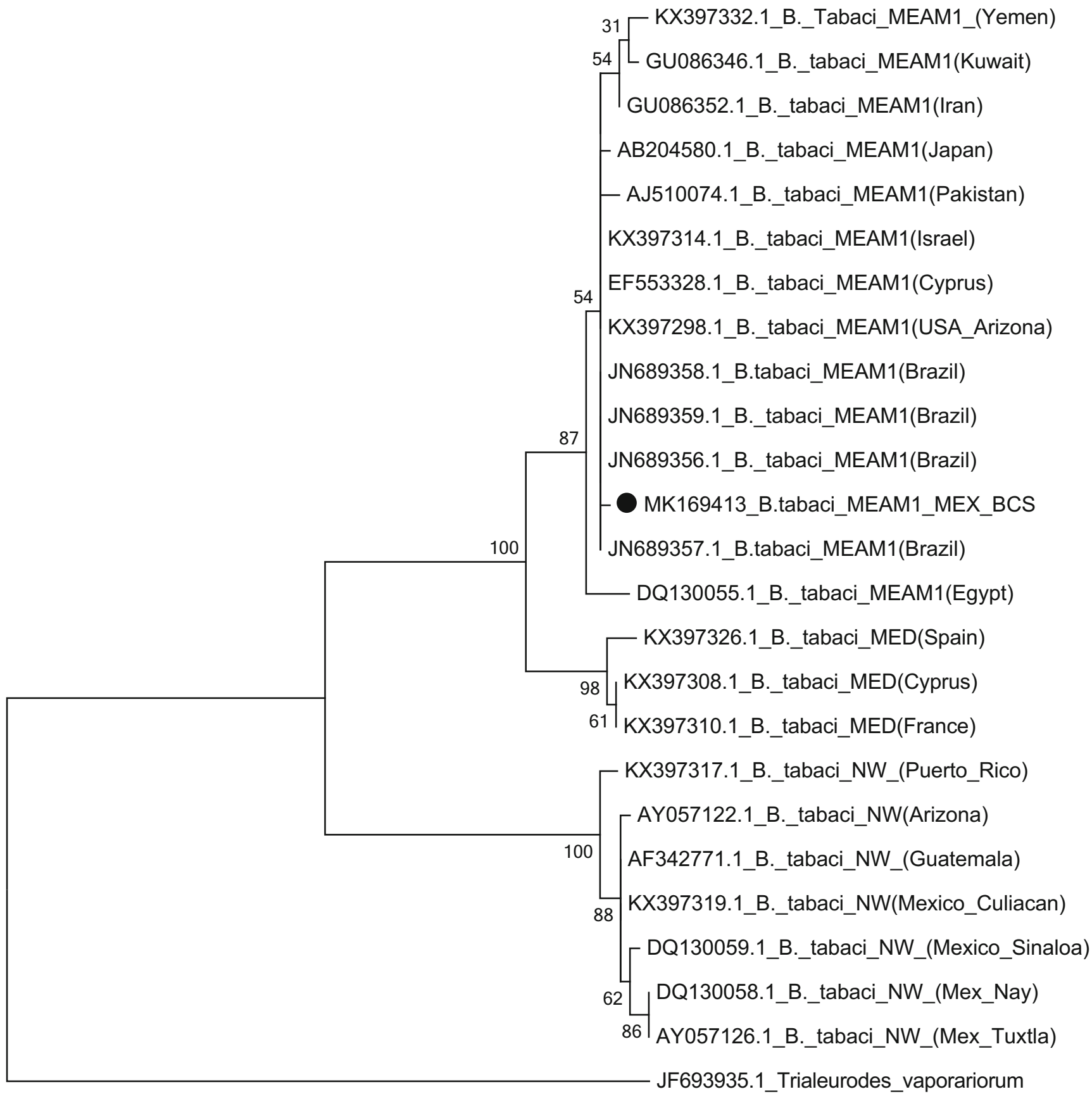

0.05

Fig. 1 Phylogenetic tree based on sequence of cytochrome oxidase I (mtCOI) fragment of B. tabaci collected in Baja California peninsula, Mexico (MEAM1_MEX_BCS), and selected reference sequences from GenBank. The alignment and phylogenetic analysis by MUSCLE

8CA, 9CA, 10CA). The whitefly symbionts were identified at genus taxonomic level for "Candidatus Portiera", Rickettsia, and Hamiltonella. To test the effect of host plant family (Solanaceae and Cucurbitaceae) on whitefly symbiont alignments coupled with maximum-likelihood (ML) methodology, based on Kimura-2 parameter model. The length of branches is supported by 1500 bootstrap replicates. Trialeurodes vaporariorum was used as outgroup

abundances, a two-way ANOVA with a Tukey post hoc test was performed. The most abundant whitefly symbiont was obligate symbiont "Candidatus Portiera" with a relative abundance range of 31.61 to $54.37 \%$; showing a slight, but not 
Table 2 Summary of sequencing analysis of $16 \mathrm{~S}$ rDNA gene of B. tabaci MEAM1 and alpha diversity indices

\begin{tabular}{lllllll}
\hline Sample ID & $N$ seqs $^{f}$ & $\begin{array}{l}\text { Total annotated } \\
\text { sequence reads* }\end{array}$ & OTUs & Simpson & Shannon & Chao1 \\
\hline 1TO & 71,158 & 70,489 & 231 & 0.98 & 2.4 & 364 \\
2CH & 72,141 & 60,259 & 187 & 0.99 & 2.3 & 274 \\
3CO & 78,712 & 78,227 & 283 & 0.94 & 2.8 & 432 \\
4H & 72,485 & 72,001 & 175 & 0.92 & 2.3 & 318 \\
5P & 79,860 & 79,329 & 129 & 0.92 & 2.4 & 249 \\
6 CA & 75,863 & 75,374 & 161 & 0.96 & 2.7 & 239 \\
7 CA & 63,917 & 63,442 & 285 & 0.82 & 2.5 & 436 \\
$8 C A$ & 88,972 & 88,372 & 168 & 0.99 & 2.7 & 202 \\
9CA & 83,919 & 83,308 & 332 & 0.93 & 2.9 & 446 \\
10CA & 52,807 & 52,459 & 142 & 0.99 & 2.3 & 337 \\
mean \pm SEM & & & $209 \pm 22$ & $0.94 \pm 0.02$ & $2.533 \pm 0.207$ & $330 \pm 28$ \\
\hline
\end{tabular}

${ }^{f}$ This column indicates total number of processed paired-end sequence reads

*This column indicates total number of annotated paired-end sequence reads significant, higher abundance in insects collected from Solanaceae (46.4-54.37\%) than those collected from Cucurbitaceae (31.61-51.05\%) (Fig. 4). The facultative symbionts showed similar abundance for both plant host families (Rickettsia, 0.011-33.69\% from Solanaceae, and 22.46$34.80 \%$ from Cucurbitaceae; and Hamiltonella, 17.93$44.2 \%$ from Solanaceae, and 17.72-31.45\% from Cucurbitaceae). The obligate symbiont ("Candidatus Portiera") overall relative abundance was significantly higher than the facultative symbionts (Rickettsia and Hamiltonella) relative abundances $(P=0.0009)$; however, host plant family did not have an effect on both obligate and facultative symbionts abundances $(P>0.05)$ (Table 3 and Fig. 4$)$.

\section{Detection and species identification of symbionts from B. tabaci MEAM1 natural populations}

The bacterial symbionts (obligate and facultative) in $\mathrm{B}$. tabaci MEAM1_MEX_BCS samples were also confirmed with PCR-based detection. We were able to detect the presence of the bacterial symbionts (obligate symbiont "Candidatus Portiera", and facultative symbionts Rickettsia and Hamiltonella) for all samples analyzed. The PCR products were sequenced, and those sequences were analyzed for species identification with "blastn" program. The obligate symbiont "Candidatus Portiera aleyrodidarum" was identified (CP016304.1, 91\% identity), as well as facultative symbionts Rickettsia sp. MEAM1 (CP016305.1), and "Candidatus Hamiltonella defense" (CP017613), with 98\% and 94\% identity, respectively. Phylogenetic analysis for the sequences corresponding for the three symbiont bacteria detected and identified in B. tabaci MEAM1_MEX_BCS for "Candidatus Portiera aleyrodidarum", "Candidatus
Hamiltonella defense", and Rickettsia sp. MEAM1 supported the metagenomic analysis results (Figs. 5, 6, and 7).

\section{Discussion}

The whitefly $B$. tabaci is an insect pest species for a wide range of crops comprising several biotypes, which are based in mtCOI gene marker. The B. tabaci feeding habit is almost restricted to plant sap obtained directly from phloem, and as a consequence, the insect requires a close association with its symbiotic bacteria. Several studies have been focused to understand the relationship of $B$. tabaci with its symbiotic bacteria, and also have been determined that there are multiple factors affecting this interaction (Pan et al. 2012; Su et al. 2016). In addition, a study conducted in a controlled environment, the diet influence was addressed onto $B$. tabaci bacterial community structures, as well as the insect biotype ( $\mathrm{Su}$ et al. 2016). And also, it has been determined that insect geographic localization is another main factor, that impacts in the insect diet, to influence on the presence of the associated symbiotic bacteria (Pan et al. 2012). We took into account that the three factors mentioned above (insect biotype, diet, and geography) influence directly onto the $B$. tabaci bacterial community structure. Hence, in the present study, we characterized natural populations of whiteflies (B. tabaci) in the Baja California peninsula south region, Mexico, applying several approaches such as identification of insect biotype, analysis of bacterial community structures associated to insects, and the identification of the obligate symbiont and facultative symbiont from insect samples (Fig. S1).

We were able to collect whitefly samples of natural populations from several localizations in the Baja California peninsula south region, and we determined that those collected 
a)

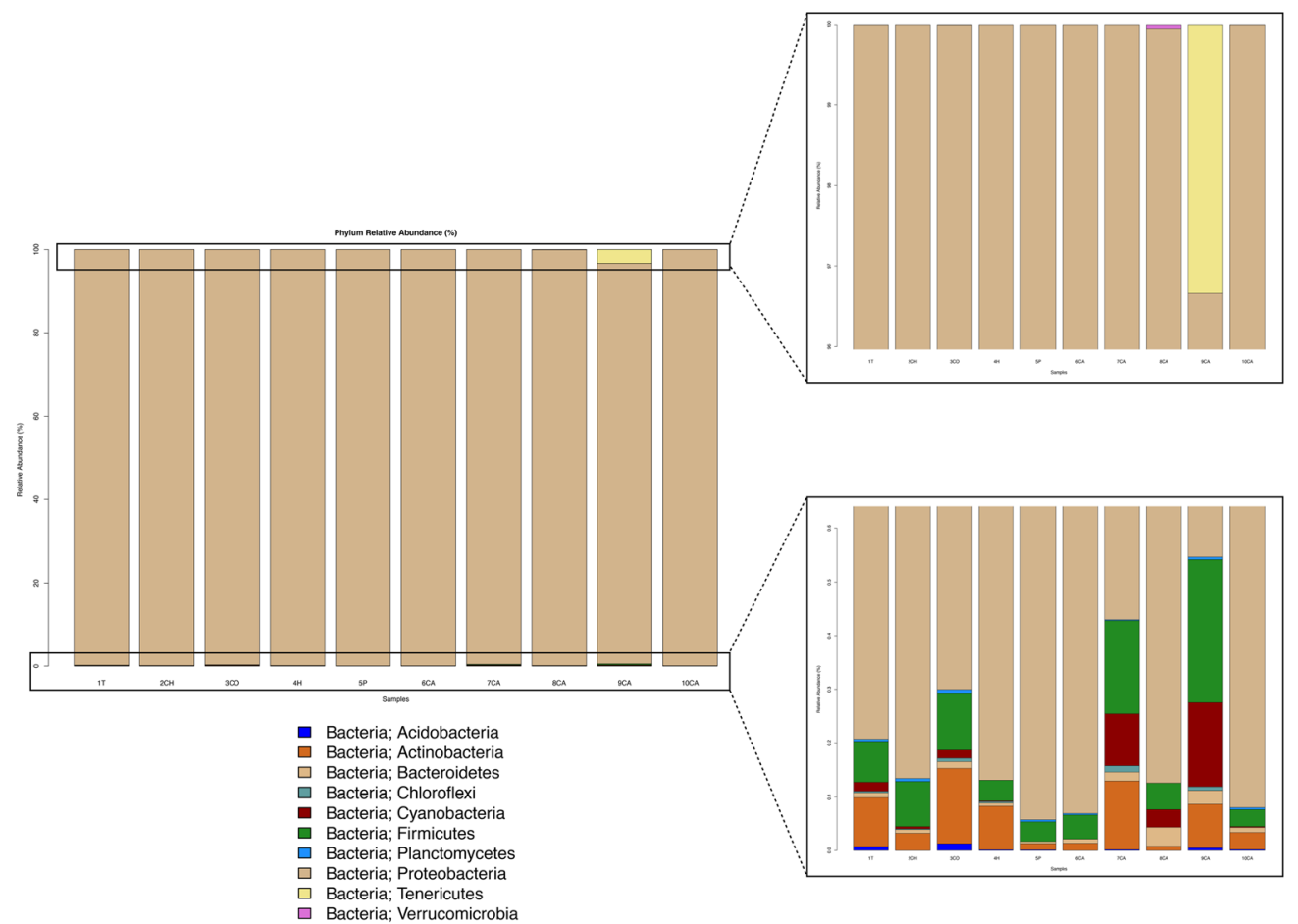

b)
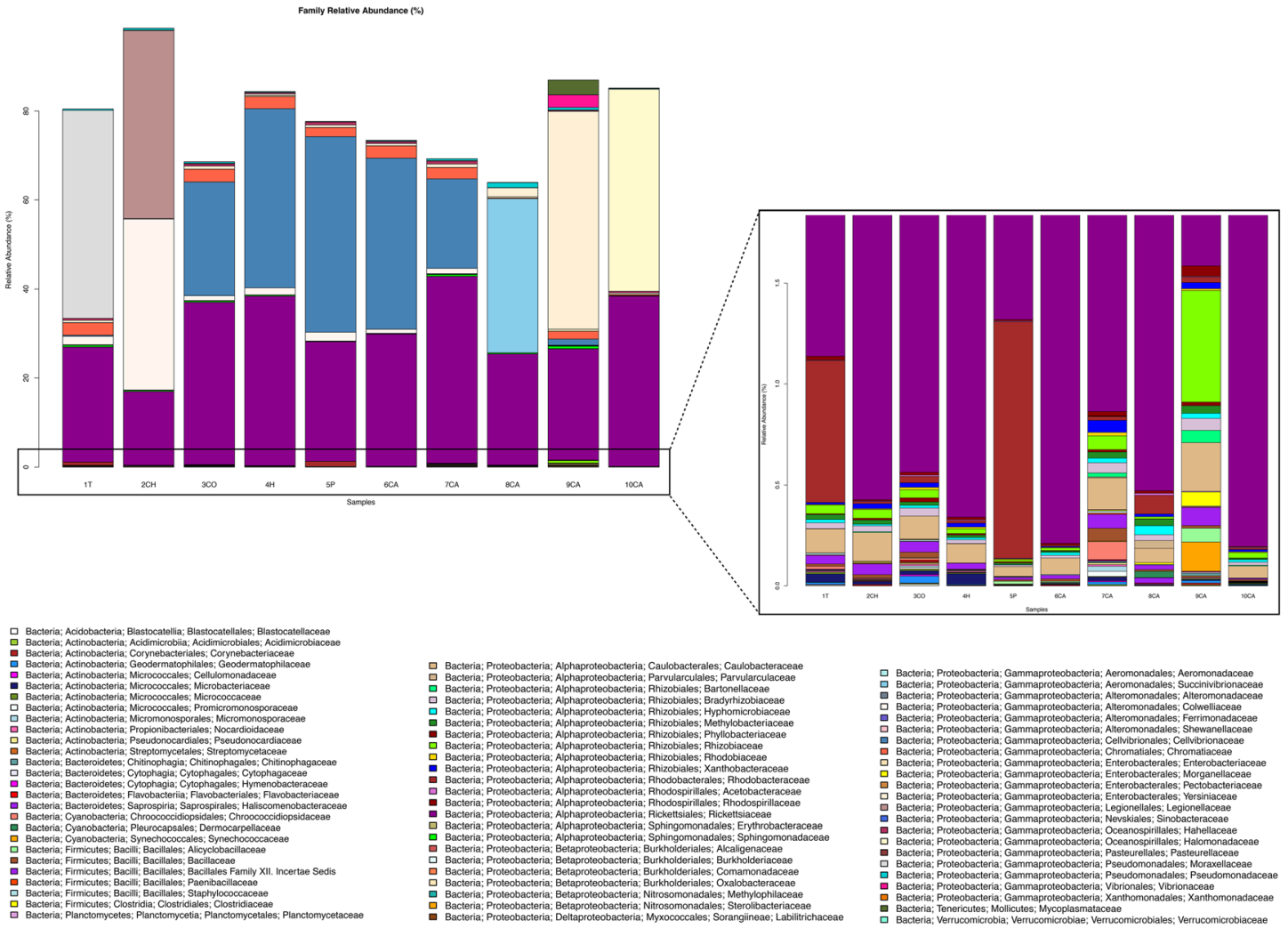

Fig. 2 Stacked column bar graph representing bacterial community composition of natural population of $B$. tabaci MEAM1_MEX_BCS based on the relative abundance at a phylum level and $\mathbf{b}$ family level (enlarged part of the low abundance associated bacteria) 


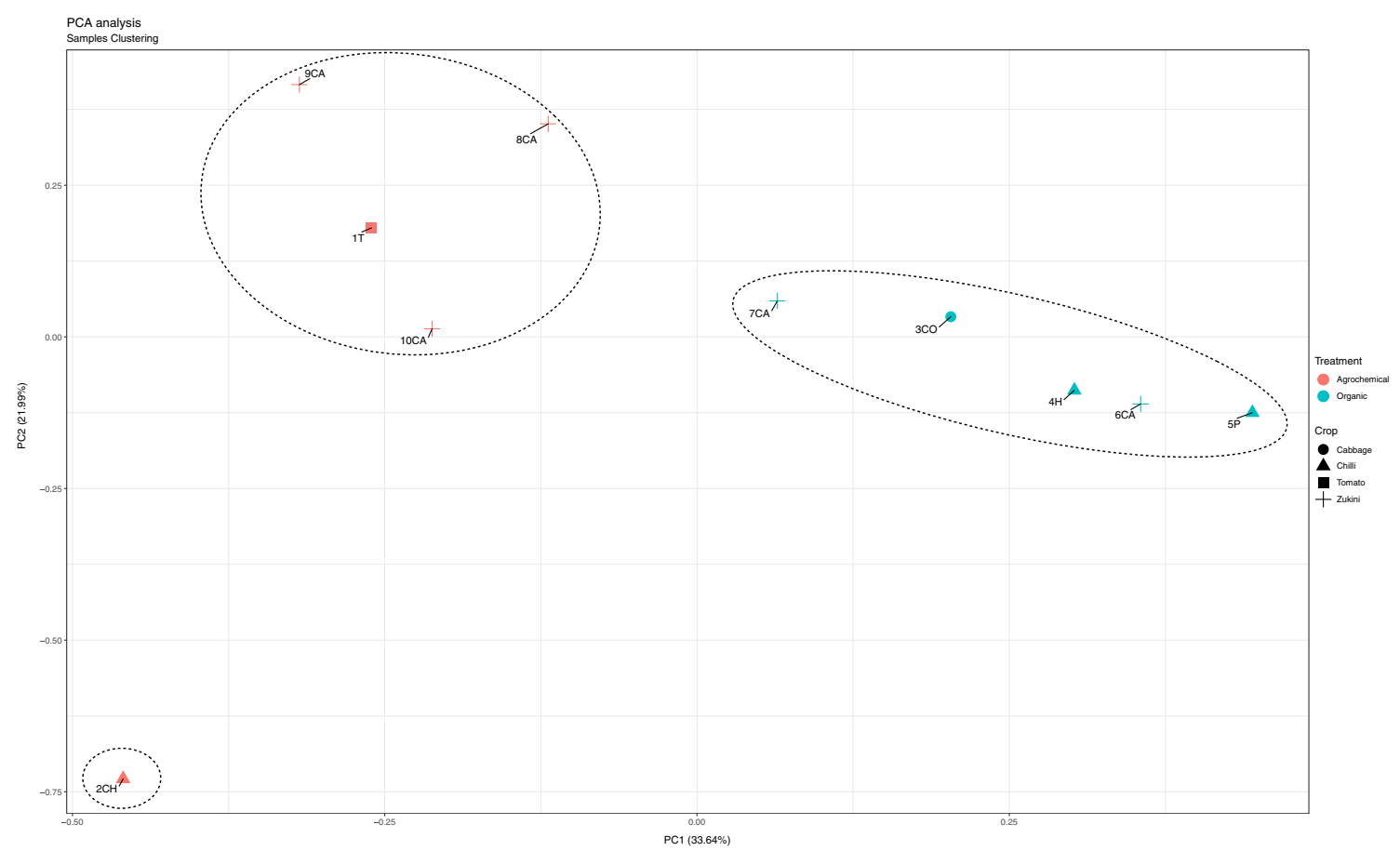

Fig. 3 Principal component analysis (PCA) of B. tabaci MEAM1_MEX_BCS bacterial community structures from natural populations of Baja California peninsula (south region), Mexico

whiteflies belong to biotype MEAM1 (Fig. 1). It is worth noting that this result was consistent with previous studies which have been shown that since the introduction of B. tabaci biotype MEAM1 in the American continent in the late $1980 \mathrm{~s}$, the native $B$. tabaci biotype NW has been displaced. The $B$. tabaci biotype MEAM1 dominance is mainly attributed to traits such as insecticide resistance, high-level polyphagia, and fecundity (Schuster et al. 2010; Smith et al. 2016; MycKenzie and Osborne 2017).

Once we have determined that $B$. tabaci natural populations from Baja California peninsula south region belong to biotype MEAM1, we proceeded to characterize the bacterial community structure associated with the whitefly by $16 \mathrm{~S}$
rDNA metagenomic analysis. The most abundant phylum was Proteobacteria (96-99\%) in the bacterial community of B. tabaci MEAM1_MEX_BCS, the remaining phyla (nine) represented abundances from $\sim 3 \%$ to less than $0.6 \%$ (Fig. 2), indicating a low richness (Shannon index) and a high homogeneity (Simpson index) (Table 2). Those results were quite similar with previous reports which were determined that phloem sap from different plant sources diet of insects contributes directly onto low bacterial richness and a homogenous structure (Jing et al. 2014; Zhao et al. 2016).

The bacterial community structures for all $\mathrm{B}$. tabaci MEAM1 samples were mainly composed by the phylum Proteobacteria; then we proceed to analyze global differences
Fig. 4 Comparison of relative abundance of the endosymbionts "Candidatus Portiera", Hamiltonella, and Rickettsia between the B. tabaci MEAM1 MEX_BCS collected from Solanaceae and Cucurbitaceae

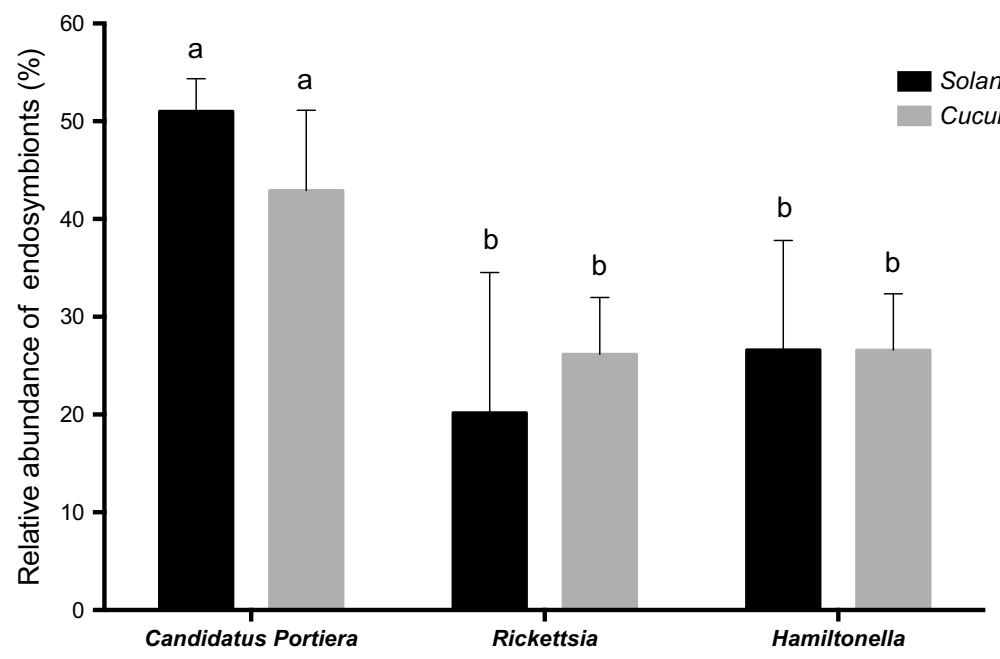


Table 3 Relative abundance (\%) of bacterial symbionts in $B$. tabaci MEAM1

\begin{tabular}{|c|c|c|c|c|c|}
\hline Sample ID & Localization & $\begin{array}{l}\text { Family of } \\
\text { host plant }\end{array}$ & $\begin{array}{l}\text { Relative } \\
\text { Portiera }\end{array}$ & $\begin{array}{l}\text { abundances } \\
\text { Rickettsia }\end{array}$ & $\begin{array}{l}(\%) \\
\text { Hamiltonella }\end{array}$ \\
\hline $1 \mathrm{TO}$ & La Matanza & S & 51.5 & 23.14 & 22.36 \\
\hline $2 \mathrm{CH}$ & La Matanza & $\mathrm{S}$ & 54.37 & 0.011 & 44.2 \\
\hline $4 \mathrm{H}$ & Comitán & $\mathrm{S}$ & 46.4 & 33.69 & 29.5 \\
\hline $5 \mathrm{P}$ & Comitán & $\mathrm{S}$ & 51.81 & 23.69 & 17.93 \\
\hline mean $\pm \mathrm{SEM}$ & & & $51.03 \pm 1.6$ & $20.13 \pm 7.13$ & $28.5 \pm 5.75$ \\
\hline $6 \mathrm{CA}$ & El Valle & $\mathrm{C}$ & 51.05 & 23.28 & 23.8 \\
\hline $8 \mathrm{CA}$ & Los Planes & $\mathrm{C}$ & 43.24 & 22.46 & 31.27 \\
\hline 9CA & Pescadero & $\mathrm{C}$ & 31.61 & 24.15 & 31.45 \\
\hline $10 \mathrm{CA}$ & Carrizal & $\mathrm{C}$ & 45.84 & 34.80 & 17.72 \\
\hline mean $\pm \mathrm{SEM}$ & & & $42.92 \pm 4.10$ & $26.17 \pm 2.89$ & $26.06 \pm 3.3$ \\
\hline
\end{tabular}

S, Solanaceae; $C$, Cucurbitaceae and similarities among all samples, to determine whether some factors may influence on to their possible clustering or not. Interestingly, the B. tabaci MEAM1 samples were clustered in two well-defined groups, and just one sample apparently did not cluster. The sample clustering was influenced by agriculture practice for crop fields, since samples 1T, 8CA, 9CA, and $10 \mathrm{CA}$ that came from crop fields with agrochemical (pesticides/organic pesticides) regular application were clustered (Fig. 3); and samples, 4H, 5P, 6CA, and 7CA that came from crop fields without agrochemical application along with $3 \mathrm{CO}$ of the Brassicaceae family were clustered in another group (Fig. 3). However, the sample $2 \mathrm{CH}$, which corresponds to $C$. annuum from crop field with agrochemical application, was grouped apart from sample $4 \mathrm{H}$ and $5 \mathrm{P}$, which also corresponds to $C$. annuum from crop field without agrochemical application, and also grouped apart from other two groups; probably, the agrochemical application induces a significant metabolic change in this plant species that also affected the B. tabaci MEAM1 bacterial community structure, as reflected in the PCA analysis (Fig. 3). This result was consistent with Zhao et al.'s (2016) study, which determined that the bacterial community structures associated to natural population of aphids are quite complex and depend upon many factors such as geographical localization, environmental factors, management/agricultural practices, and natural enemies that as a whole may be referred as the selection pressures (Boush and Matsumura 1967; Kikuchi et al. 2012; Werren 2012; Kakumanu et al. 2016; Cheng et al. 2017; Gressel 2018; Xia et al. 2018; Vijayakumar et al. 2018).

In addition, it is worth noting that our metagenomic analysis also showed that an important proportion of the reads was assigned to the obligate symbiont "Candidatus Portiera" (a quarter to more than a half) and for the facultative symbionts Hamiltonella and Rickettsia (from one-thousandth to more than two-fifths), for which both "Candidatus Portiera" and Hamiltonella genera belong to Gammaproteobacteria class,

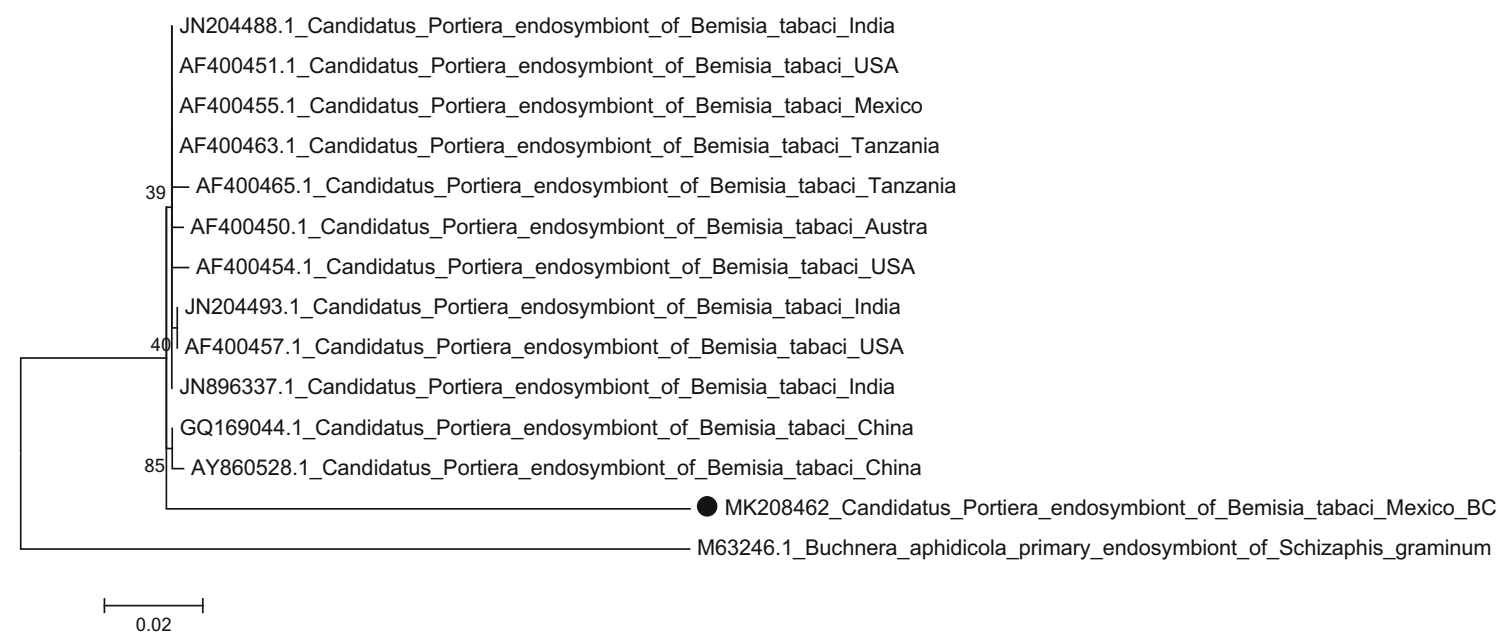

Fig. 5 Phylogenetic tree based on sequence of 16S rDNA of "Candidatus Portiera" fragment obtained from B. tabaci MEAM1_MEX_BCS, and selected reference sequences from GenBank. The alignment and phylogenetic analysis by MUSCLE alignments coupled with maximum-likelihood (ML) methodology, based on Kimura-2 parameter model. The length of branches is supported by 1000 bootstrap replicates. Buchnera aphidicola endosymbiont of Schizaphis graminum was used as outgroup 


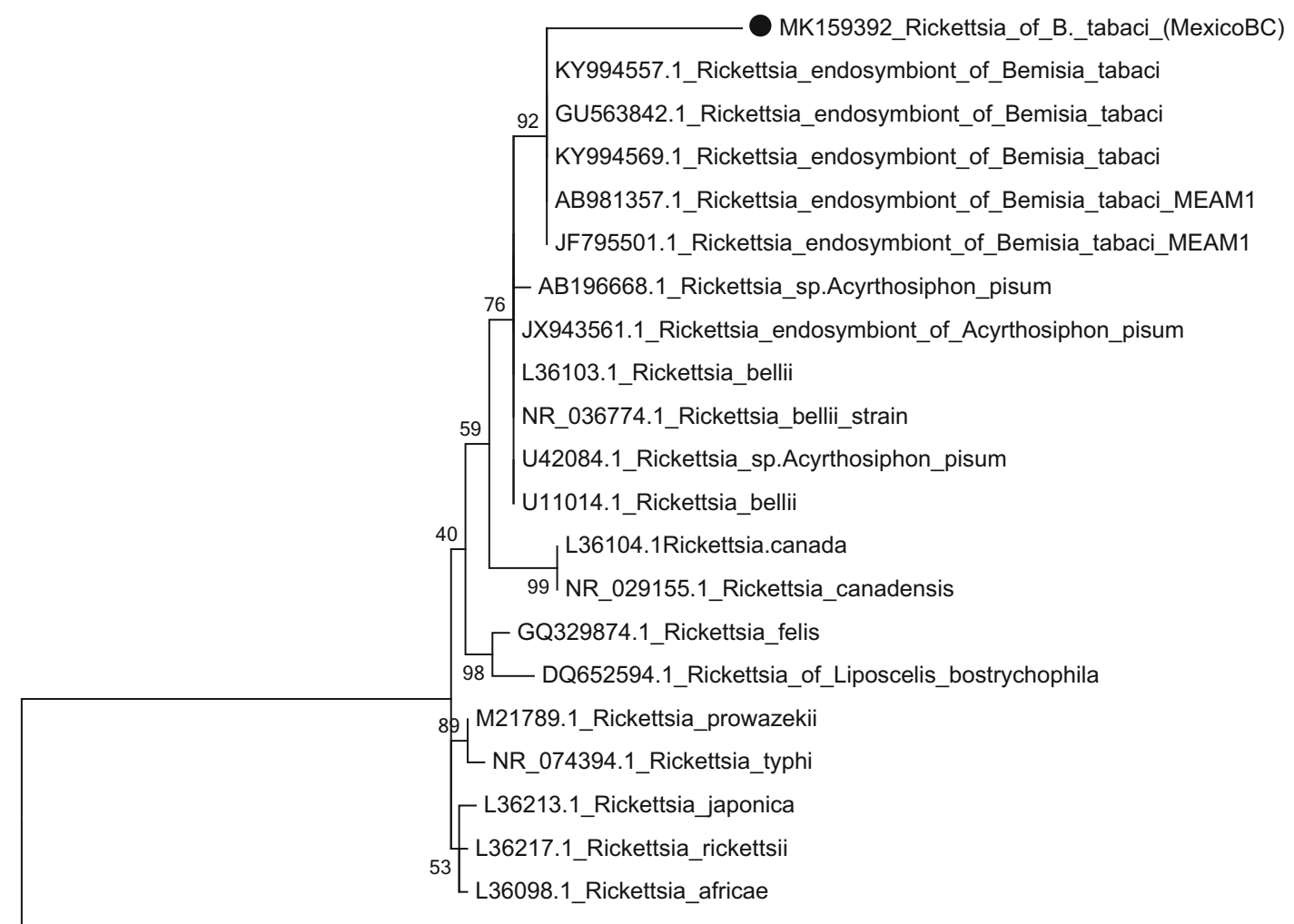

AY850932.1_Wolbachia_endosymbiont_of_Bemisia_tabaci

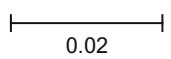

Fig. 6 Phylogenetic tree based on sequence of 16S rDNA of Rickettsia endosymbiont fragment obtained from B. tabaci collected in Baja California peninsula, Mexico (MEAM1_MEX_BCS), and selected

and Rickettsia genus belongs to Alphaproteobacteria class; and in turn, these genera become the main constituents of the bacterial community structures from whiteflies $B$. tabaci MEAM1 reference sequences from GenBank. The number on the branches represents bootstrap values for 1500 replicates. Wolbachia endosymbiont of $B$. tabaci was used as outgroup sequences

natural populations. The importance of the bacterial interaction with insects such as symbionts (obligate and/or facultative) is essential for host survival, since those bacteria are required for

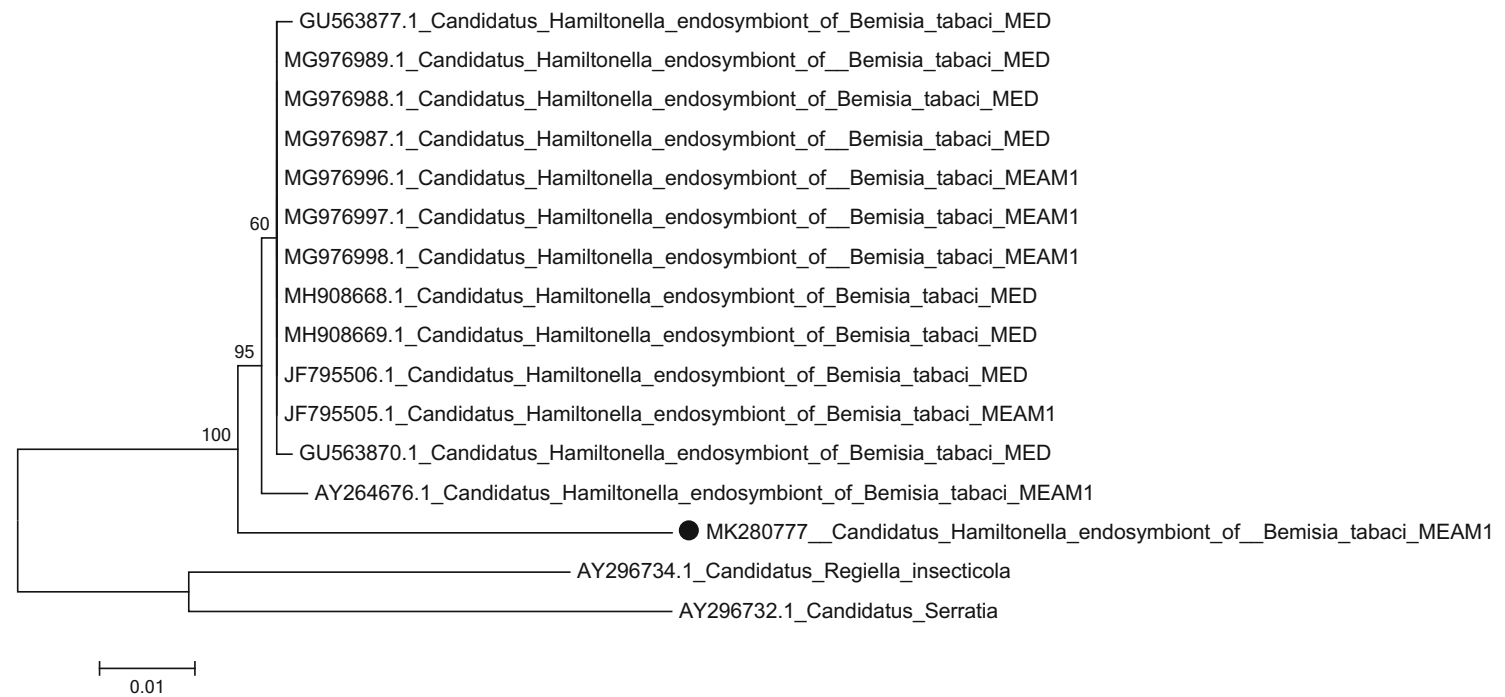

Fig. 7 Phylogenetic tree based on sequence of $16 \mathrm{~S}$ rDNA of "Candidatus Hamiltonella" fragment obtained from B. tabaci MEAM1_MEX_BCS, and selected reference sequences from GenBank. The length of branches is supported by 1500 bootstrap replicates. "Candidatus Regiella" and "Candidatus Serratia" endosymbiont of aphids was used as outgroup 
the synthesis of essential amino acids and hence allows the insect to feed on a phloem-based diet (Su et al. 2014; Upadhyay et al. 2015; Chen et al. 2016; Liu et al. 2016; Zhang et al. 2016).

Finally, the whiteflies B. tabaci MEAM1 bacterial community structures were not only influenced by their feeding habits of an entirely phloem-based diet, but also the crop plants have an impact over their bacterial symbiont distributions. We were able to determine a slight bias (not significant) on the facultative symbionts (Hamiltonella and Rickettsia) relative abundance in a crop-independent manner (excepting sample $2 \mathrm{CH}$, Solanaceae, Table 3). Interestingly, the obligate symbiont ('Candidatus Portiera') practically was not affected by the feeding of different crops of the insect (Table 3). Therefore, the endosymbiont relative abundances from whiteflies B. tabaci MEAM1 natural populations were not affected by the host plant in field conditions, contrasting with previous reports for other whiteflies $B$. tabaci biotype MED and other aphids at in vitro conditions (Pan et al. 2013; Liu et al. 2016).

\section{Conclusions}

The geographic localization and diet of whiteflies natural populations in Baja California Sur had a direct effect to maintain their bacterial community structure, since the main phyla and classes were Proteobacteria, Alphaproteobacteria, and Gammaproteobacteria, respectively, as reported previously for other whiteflies around the world. However, agricultural practices (agrochemicals application) were a factor that influenced on the bacterial community structure at family taxonomic level, and also was reflected in different clustering analyses. The insect host plants also did not have an impact on to the endosymbiont relative abundances, in spite of sap nutrient differences. Finally, to achieve a deeper understanding of the bacterial community structures of whiteflies and the functional role that those carried out in conjunction with the symbionts inside this insect pest, further investigation is necessary.

Acknowledgments We thank Jaime Holguín-Peña, Martín Aguilar, Saúl Briceño for technical support for insect samples collections. Angel Carrillo-Garcia and Patricia Hinojosa-Baltazar for technical assistance. Paul Gaytan, Jorge Yañéz, and Eugenio López for primer synthesis and sequencing at Instituto de Biotecnología, Universidad Nacional Autónoma de México. Bruno Gomez-Gil for 16S V3 rDNA sequencing at Laboratorio de Genómica Microbiana, CIAD-Mazatlán, México.

Funding The current investigation was supported by CONACYT/ Mexico through the funds provided to CIBNOR.

\section{Compliance with ethical standards}

Conflict of interest The authors declare that they have no conflict of interest.
Research involving human participants and/or animals This research does not involve animals or humans.

Informed consent N/A

\section{References}

Azab AK, Megahed MM, E Mirsawi HD (1969) Studies on Bemisia tabaci (Genn.) (Hemiptera Homoptera: Aleyrodidae). Bull Entomol Soc Egypt 53:339-351

Boush MG, Matsumura F (1967) Insecticidal degradation by Pseudomonas melophthora, the bacterial symbiote of the apple maggot. J Econ Entomol 60:918-920. https://doi.org/10.1093/jee/ 60.4 .918

Boykin LM, Shatters RG, Rosell RC, McKenzie CL, Bagnall RA, Bagnall RA, De Barro P (2007) Global relationships of Bemisia tabaci (Hemiptera: Aleyrodidae) revealed using Bayesian analysis of mitochondrial COI DNA sequences. Mol Phylogenet Evol 44: 1306-1319. https://doi.org/10.1016/j.ympev.2007.04.020

Boykin LM, Bell CD, Evans G, Small I, Barro PJ (2013) Is agriculture driving the diversification of the Bemisia tabaci species complex (Hemiptera:sternorrhyncha:Aleyrodidae)?:dating diversification and biogeographic evidence revealed. BMC Evol Biol 13:228. https://doi.org/10.1186/1471-2148-13-228

Brumin M, Kontsedalov S, Ghanim M (2011) Rickettsia influences thermotolerance in the whitefly Bemisia tabaci B biotype. Insect Sci 18: 57-66. https://doi.org/10.1111/j.1744-7917.2010.01396x

Bushnell B, Rood J, Singer E (2017) BBmerge - accurate paired shotgun read merging via overlap. PLoS One 12(10):e0185056. https://doi.org/10.1371/journal.pone.0185056

Castañeda LE, Barbosa O (2017) Metagenomic analysis exploring taxonomic and functional diversity of soil microbial communities in Chilean vineyards and surrounding native forests. PeerJ 5:e3098. https://doi.org/10.7717/peerj.3098

Chen W, Hasegawa D, Arumuganathan K, Simmons AM, Wintermantel WM, Fei Z, Ling KS (2015) Estimation of the whitefly Bemisia tabaci genome size based on k-mer and flow cytometric analyses. Insects 6:704-715. https://doi.org/10.3390/insects6030704

Chen B, The BS, Sun C, Hu S, Lu X, Boland W, Shao Y (2016) Biodiversity and activity of the gut microbiota across the life history of the insect herbivore Spodoptera littoralis. Sci Rep 6:29505. https://doi.org/10.1038/srep29505

Cheng D, Guo Z, Riegler M, Xi Z, Liang G, Xu Y (2017) Gut symbiont enhances insecticide resistance in a significant pest, the oriental fruit fly Bactrocera dorsalis (Hendel). Microbiome 5: 13. https://doi.org/10.1186/s40168-017-0236-z

Chrostek E, Pelz-Stelinski K, Hurst GDD, Hughes GL (2017) Horizontal transmission of intracelular insect symbionts via plants. Front Microbiol 8:2237. https://doi.org/10.3389/fmicb.2017.02237

Chuche J, Auricau-Bouvery N, Jean-Luc D, Thiery D (2017) Use the insiders: could insect facultative symbionts control vector-borne plant diseases? J Pest Sci 90:51-68. https://doi.org/10.1007/ s10340-016-0782-3

Chung SH, Scully ED, Peiffer M, Geib S, Rosa C, Hoover K, Felton GW (2017) Host plant species determines symbiotic bacterial community mediating suppression of plant defenses. Sci Rep 7:39690. https://doi.org/10.1038/srep39690

Coleman-Derr D, Desgarennes D, Fonseca-Garcia C, Gross S, Clingenpeel S, Woyke T, North G, Visel A, Partida-Martinez LP, Tringe SG (2016) Plant compartment and biogeography affect microbiome composition in cultivated and native Agave species. New Phytol 209:798-811. https://doi.org/10.1111/nph.13697 
De Barro PJ, Liu SS, Boykin LM, Dinsdale AB (2011) Bemisia tabaci: a statement of species status. Annu Rev Entomol 56: 1-19. https://doi.org/10.1146/annurev-ento-112408-085504

Elfekih S, Etter P, Tay WT, Fumagalli M, Gordon K, Johnson E, De Barro P (2018) Genome-wide analyses of the Bemisia tabaci specie complex reveal contrasting patterns of admixture and complex demographic histories. PLoS One 13(1):e0190555. https://doi.org/10. 1371/journal.pone.0190555

Ewing B, Green P (1998) Base-calling of automated sequences traces using phred II. Genome Res 8:186-194. https://doi. org/10.1101/gr.8.3.186

Ewing B, Hillier L, Wendl MC, Green P (1998) Base-calling of automated sequencer traces using phred I. accuracy assessment. Genome Res 8:175-185. https://doi.org/10.1101/gr.8.3.175

Gnankiné O, Mouton L, Henri H, Terraz G, Houndeté T, Martin T, Vavre F, Fleury F (2013) Distribution of Bemisia tabaci (Homoptera: Aleyrodidae) biotypes and their associated symbiotic bacteria on host plants in West Africa. Insect Conserv Divers 6:411-421. https://doi.org/10.1111/j.1752-4598.2012.00206.x

Gressel J (2018) Microbiome facilitated pest resistance potential problem and uses. Pest Manag Sci 74:511-515. https://doi. org $/ 10.1002 / p s .4777$

Hendry TA, Hunter MS, Baltrus DA (2014) The facultative symbiont Rickettsia protects an invasive whitefly against entomopathogenic Pseudomonas syringae strains. Appl Environ Microbiol 80:71617168. https://doi.org/10.1128/AEM.02447-14

Jing X, Wong A, Chaston JM, Colvin J, Mckenzie CL, Douglas A (2014) The bacterial communities in plant phloem sap feeding insects. Mol Ecol 23:1433-1444. https://doi.org/10.1111/mec.12637

Kakumanu ML, Reeves AM, Anderson TD, Rodrigues RR, Williams MA (2016) Honey bee gut microbiome is altered by in-hive pesticide exposures. Front Microbiol 7:1255. https://doi.org/10.3389/ fmicb.2016.01255

Kearse M, Moir R, Wilson A, Stones-Havas S, Cheung M, Sturrock S, Buxton S, Cooper A, Markowitz S, Duran C, Thierer T, Ashton B, Meintjes P, Drummond A (2012) Geneious basic: an integrated and extendable desktop software platform for the organization and analysis of sequence data. Bioinformatics 28(12): 1647-1649. https://doi.org/10.1093/bioinformatics/bts199

Kikuchi Y, Hayatsu M, Hosokawa T, Nagayama A, Tago K, Fukatsu T (2012) Symbiont-mediated insecticide resistance. Proc Natl Acad Sci U S A 109:8618-8622. https://doi.org/10.1073/pnas. 1200231109

Kostic AD, Howitt MR, Garrett WS (2013) Exploring host-microbiota interactions in animal models and humans. Genes Dev 27(7):701718. https://doi.org/10.1101/gad.212522.112

Kumar S, Stecher G, Tamura K (2016) MEGA7: molecular evolutionary genetics analysis version 7.0 for bigger datasets. Mol Biol Evol 33(7):1870-1874. https://doi.org/10.1093/ molbev/msw054

Li YH, Ahmed MZ, Li SJ, Lv N, Shi PQ, Chen XS, Qiu BL (2017a) Plant mediated horizontal transmission of Rickettsia endosymbiont between different whitefly species. FEMS Microbiol Ecol 93(12). https://doi.org/10.1093/femsec/fix138

Li SJ, Ahmed MZ, LV N, Shi PQ, Wang XM, Huang JL, Qiu BL (2017b) Plant mediated horizontal transmission of Wolbachia between whiteflies. ISME J 11:1019-1028. https://doi.org/10.1038/ismej. 2016.164

Liu YH, Kang ZW, Guo Y, Zhu GS, Shah MMR, Song Y, Fan YL, Jing X, Liu TX (2016) Nitrogen hurdle of host alternation for a polyphagous aphid and the associated changes of endosymbionts. Sci Rep 6:24781. https://doi.org/10.1038/srep24781
Mereghetti V, Chouaia B, Montagna M (2017) New insights into the microbiota of moth pests. Int J Mol Sci 18(11):2450. https://doi.org/10.3390/ijms18112450

Meyer F, Paarmann D, D'Souza M, Olson R, Glass EM, Kubal M, Paczian T, Rodriguez A, Stevens R, Wilkening J, Edwards RA (2008) The metagenomics RAST server -a public resource for the automatic phylogenetic and functional analysis of metagenomes. BMC Bioinformatics 19(9):386. https://doi.org/10.1186/14712105-9-386

MycKenzie CL, Osborne L (2017) Bemisia tabaci MED (Q biotype) is on the move in Florida to residential landscapes and may impact open field agriculture. Fla Entomol 100:481-485. https://doi.org/10.1653/ 024.100 .0213

Oksanen J, Blanchet FG, Kindt R, Legendre P, Minchin PR, O'hara RB, Simpson GL, Solymos P, Stevens MHH, Wagner H (2014) Vegan: community ecology package. $\mathrm{R}$ package version 2.2-0. http://CRAN.Rproject.org/package=vegan

Pan H, Li X, Ge D, Wang S, Wu Q, Xie W, Jiao X, Chu D, Liu B, Xu B, Zhang Y (2012) Factors affecting population dynamics of maternally transmitted endosymbionts in Bemisia tabaci. PLoS One 7(2): e30760. https://doi.org/10.1371/journal.pone.0030760

Pan H, Su Q, Jiao X, Zhou L, Liu B, Xie W, Wang S, Wu Q, Xu B, Zhang Y (2013) Relative amount of symbionts in Bemisia tabaci (Gennadius) Q changes with host plant and establishing the method of analyzing free amino acid in B. tabaci. Commun Integr Biol 6: e23397. https://doi.org/10.4161/cib.23397

Randle-Boggis RJ, Helgason T, Sapp M, Ashton PD (2016) Evaluating techniques for metagenome annotation using simulated sequence data. FEMS Microbiol Ecol 92(7):fiw095. https://doi.org/10.1093/ femsec/fiw095

Rosell RC, Lichty JE, Brown JK (1995) Ultrastructure of the mouthparts of adult sweetpotato whitefly, Bemisia tabaci Gennadius (Homoptera:Aleyrodidae). Int J Insect Morphol Embryol 24:297-306

Schuster DJ, Rajinder SM, Toapanta M, Cordero R, Thompson S, Cyman S, Shurtleff A, Morris RF (2010) Monitoring neonicotinoid resistance in biotype B of Bemisia tabaci in Florida. Pest Manag Sci 66: 186-195. https://doi.org/10.1002/ps.1853

Shatters RG, Powell C, Boykin LM, Liansheng H, McKenzie CL (2009) Improved DNA barcoding method for Bemisia tabaci and related Aleyrodidae:development of universal and Bemisia tabaci biotype specific mitochondrial cytochrome c oxidase I polymerase chain reaction primers. J Econ Entomol 102:750-758. https://doi.org/10. 1603/029.102.0236

Smith HA, Nagle CA, MacVean CA, McKenzie CL (2016) Susceptibility of Bemisia tabaci MEAM1 (Hemiptera: Aleyrodidae) to imidacloprid, thiamethoxam, dinotefuran and flupyradifurone in south Florida. Insects 7(4):57. https://doi. org/10.3390/insects 7040057

Su Q, Pan H, Liu B, Chu D, Xie W, Wu Q, Wang S, Xu B, Zhang Y (2013) Insect symbiont facilitates vector acquisition, retention, and transmission of plant virus. Sci Rep 3:1367. https://doi.org/10.1038/ srep01367

Su Q, Xie W, Wang S, Wu Q, Liu B, Fang Y, Zhang Y (2014) The endosymbiont Hamiltonella increases the growth rate of its host Bemisia tabaci during periods of nutritional stress. PloS one 9(2): e89002. https://doi.org/10.1371/journal.pone.0089002

Su Q, Oliver KM, Xie W, Wu Q, Wang S, Zhang Y (2015) The whiteflyassociated facultative symbiont Hamiltonella defensa suppresses induced plant defences in tomato. Funct Ecol 29: 1007-1018. https://doi.org/10.1111/1365-2435.12405

Su MM, Guo L, Tao YL, Zhang YJ, Wan FH, Chu D (2016) Effect of host plant factor on the bacterial communities associated with two 
whitefly sibling species. PLoS One 11:e0152183. https://oi.org/10. 1371/journal.pone. 0152183

Upadhyay SK, Sharma S, Singh H, Dixit S, Kumar J, Verma PC, Chandrashekar K (2015) Whitefly genome expression reveals host-symbiont interaction in amino acid biosynthesis. PLoS One 10(5):e0126751. https://doi.org/10.1371/journal.pone. 0126751

Vijayakumar MM, More RP, Rangasamy A, Gandhi GR, Muthugounder M, Thiruvengadam V, Samaddar S, Jalali S, Sa T (2018) Gut bacterial diversity of insecticide-susceptible and resistant nymphs of the brown planthopper Nilaparvata lugens stal (Hemiptera: Delphacidae) and the elucidation of their putative functional roles. J Microbiol Biotechnol 28:976-986. https://doi.org/10.4014/jmb. 1711.11039

Weiss B, Aksoy S (2011) Microbiome influences on insect host vector competence. Trends Parasitol 27(11):514-522. https://doi.org/10. 1016/j.pt.2011.05.001

Werren JH (2012) Symbionts provide pesticide detoxification. Proc Natl Acad Sci U S A 109:8364-8365. https://doi.org/10.1073/pnas. 1206194109
Xia X, Sun B, Gurr GM, Vasseur L, Xue M, You M (2018) Gut microbiota mediate insecticide resistance in the diamondback moth, Plutella xylostella (L.). Front Microbiol 9:25. https://doi.org/10. 3389/fmicb.2018.00025

Zhang YC, Cao WJ, Zhong LR, Godfray HCJ, Liu XD (2016) Host plant determines the population size of an obligate symbiont (Buchenera aphidicola) in aphids. Appl Environ Microbiol 82:2336-2346. https://doi.org/10.1128/AEM.04131-15

Zhao Y, Zhang S, Luo JY, Wang CY, Lv LM, Cui JJ (2016) Bacterial communities of the cotton aphid Aphis gossypii associated with BT cotton in northern China. Sci Rep 6:22958. https://doi.org/10.1038/ srep22958

Zhu YX, Song YL, Zhang YK, Hoffmann AA, Zhou JC, Sun JT, Hong $\mathrm{XY}$ (2018) Incidence of facultative bacterial endosymbionts in spider mites associated with local environments and host plants. Appl Environ Microbiol 84(6):e02546-e02517. https://doi.org/10.1128/ AEM.02546-17

Publisher's Note Springer Nature remains neutral with regard to jurisdictional claims in published maps and institutional affiliations. 